\title{
Florestan Fernandes e a teoria da revolução burguesa no Brasil
}

\section{Florestan Fernandes and the theory of the bourgeois revolution in Brazil}

\author{
Jaldes Meneses ${ }^{a}$ \\ (i) https://orcid.org/0000-0002-1411-0396
}

Resumo: Este artigo se propõe a examinar, na oportunidade do centenário de nascimento (1920) e de 45 anos de publicação de $A$ revolução burguesa no Brasil (1975), a originalidade da interpretação de Brasil esboçada por Florestan Fernandes, especialmente em categorias como "ordem social”, essencial para compreender nosso passado e para esboçar novos grandes painéis interpretativos de processo e de história. Para entender essa complexa trama, é fundamental mergulhar no particularíssimo método de investigação e exposição do autor, bem como confrontá-lo com sua vivência e formação na época do Brasil pós-1930 até a conjuntura de publicação do livro.

Palavras-chave: Florestan Fernandes. Revolução burguesa no Brasil. Ordem Social.

\begin{abstract}
This article aims to examine, in the 25 years anniversary of the release of The bourgeois revolution in Brazil (1975) and the centenary of Florestan Fernandes (1920), the originality of his interpretation of Brazil, especially the definition of "social order", essential to understand our past and to outline new great interpretative panels of process and history. To comprehend this complex plot, it is crucial to immerse in the author's very particular method of investigation and exposure and also correlate with his experience living in 1930 until the release of the book.
\end{abstract}

Keywords: Florestan Fernandes. The borgueois revolution in Brazil. Social Order. 


\section{Introdução: A revolução burguesa no Brasil na oportunidade do "refluxo da contrarrevolução"}

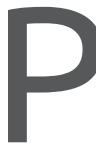

rofessor universitário socialmente respeitado e militante de esquerda, na época, sem partido definido, adversário da ditadura militar de 1964, dez anos depois da instauração da ditadura (1974), Florestan Fernandes (cujo centenário de nascimento se comemorou em 22/7/2020) pincelava os retoques finais na máquina de escrever de um livro ambicioso, A revolução burguesa no Brasil (sigla RBB), cujos 45 anos se comemoraram também no ano de 2020.

A obra despertou um vigoroso debate acadêmico no exterior, em meio de brasilianistas, impossível de aflorar em plena ditadura livremente em universidades brasileiras. Já em 1976, a University of Texas em Austin realizou um Colóquio coordenado pelos professores Carlos Guilherme Mota (USP) e Fred P. Ellison (Vários autores, 1978, p. 176-207). Também despertou o interesse de outro mundo, a esquerda revolucionária. Segundo Anita Prestes, a leitura de Florestan foi uma das fontes de seu pai, Luís Carlos Prestes, Secretário-Geral do PCB (Partido Comunista Brasileiro), no questionamento sobre a linha dominante no "partidão", que ele mesmo ajudou a predominar, ao subscrever a Declaração de Março de 1958, o V Congresso (1960) e acatar a linha - em que pesem as críticas intramuros - do VI Congresso (1967), que racharam o partido (Gorender, 1987a, p. 25-32). O PCB, até aquela data o partido mais influente na esquerda brasileira, entrou em modo irremediável de crise de identidade. A estratégia nacional e democrática e o corolário da conquista de um capitalismo autônomo no Brasil, por meio de uma aliança anti-imperialista e antilatifundiária entre os trabalhadores e a burguesia nacional (mais bem definida, por falta de projeto nacional autônomo, como burguesia interna ou brasileira), de consecução de uma etapa estratégica de alianças policlassistas de longo prazo, foram derrotados pelo golpe de 1964. Embora passível de críticas, a linha etapista fazia sentido — na aparência do processo político até 1964 —, o que, até certo ponto, justificava o empenho de Prestes e de outros seus camaradas. 
A eventual e relativa aderência à realidade da linha etapista se exauria na década de 1970 devido à conclusão do processo das "transformações capitalistas” (Fernandes, 1987, p. 337-424) encaminhadas pela ditadura - "se já houve, alguma vez, um 'paraíso burguês', este existe no Brasil, pelo menos depois de 1968” (Fernandes, 1987, p. 359). Exilado na União Soviética, o velho secretário recomeçou a estudar autocriticamente a realidade brasileira: "esse esforço de leitura é comprovado pelas numerosas fichas e anotações de leituras [...] tanto de obras dos clássicos do marxismo quanto de autores brasileiros contemporâneos, entre os quais os escritos do sociólogo Florestan Fernandes" (Prestes, 2012, p. 190).

Exemplo de persistência da linha tradicional de replicar aqui uma revolução nacional burguesa, neste caso a postulação de uma etapa de aliança estratégica relativamente longa entre a burguesia e o proletariado, na mesma conjuntura de RBB, Nelson Werneck Sodré escreveu: "quanto à necessidade de 'previamente, da revolução burguesa' [...] uma coisa é a realidade, outra coisa é o desejo: não se trata de opinar sobre a necessidade 'prévia' da revolução burguesa no Brasil; trata-se de constatá-la” (Sodré, 1985, p. 749). Já o próprio Prestes, em depoimento no Instituto Cajamar, afirmou peremptoriamente: "em 1945, os documentos de nosso partido diziam que, enquanto não acabasse a dominação imperialista, o feudalismo e o latifúndio, o capitalismo não se desenvolveria no país. Negávamos subjetivamente o capitalismo em 1945, quando o governo federal já estava construindo a grande usina siderúrgica de Volta Redonda. O que nos esclareceu foram as obras dos sociólogos a que eu já me referi, mas publicadas somente muito depois. É o caso de Capitalismo dependente e classes sociais na América Latina, A revolução burguesa no Brasil, em que Florestan Fernandes mostra como se deu a penetração imperialista em nosso país, conservando as relações anteriores [...]" (Prestes, 1988, p. 233). O contraste de visão de Brasil dos dois autores, relativo a uma estratégia de revolução burguesa, é irredutível.

Naquele mesmo ano de 1974, quando a Editora Zahar preparava os originais de RBB, assumia a Presidência da República o general Ernesto Geisel, com projetos de fazer uma transição política controlada 
e conservadora da ditadura a um regime civil. Na oposição, era tempo de recomeçar, de acumular forças. Para Florestan, aquela conjuntura de recomeço, por outro lado, abriu a oportunidade de um "refluxo na contrarrevolução" e a possibilidade de um reagrupar das "forças socialistas" (Fernandes, 1980a, p. 1). Portanto, abriu-se a brecha de produzir uma publicística revolucionária de esquerda. Deve-se observar que as forças do socialismo foram dispersas pelas seguidas derrotas impostas pela repressão - especialmente pela eliminação física de quadros dos partidos revolucionários - , enquanto, no trato das forças democráticas (em que pesem cassações, torturas e mortes, mais rarefeitas, também nesse campo), houve mais uma combinação de controle e repressão, sempre contando com uma réstia de atuação política consentida nos marcos do MDB.

Estava em causa na conjuntura de "refluxo da contrarrevolução" muito mais que a transação de um novo lugar da corporação militar na composição do novo bloco no poder democratizado. Assim, a realização do processo de revolução burguesa pela "geração de 1930", no livro e na realidade, enfim estacionava no porto morto da ilusão do desenvolvimento prometido. Ali, na plenitude da "transformação capitalista do modelo autocrático-burguês”, dava-se à luz — que se tornaria escancarado duas décadas adiante - um "ornitorrinco", uma espécie que parou a evolução e se transformou num híbrido, o único mamífero ovíparo existente, metáfora dos destinos do desenvolvimentismo brasileiro, que, a partir de certa hora, viu-se com o seguinte dilema em frente ao espelho: fênix ou extinção? (Oliveira, 2003a, p. 121-150; 2003b, p. 109-116).

A análise de Florestan é radical. Ele, fosse vivo, relembraria que o "ornitorrinco" é um ponto de chegada cujo DNA já estava inscrito no ponto de partida, não por circularidade, mas por história. Desde cedo, nosso autor observou que as classes dominantes brasileiras não apenas são resistentes à mudança social, mas também desenvolvem resistências — prestem atenção à palavra 'sociopáticas' - à mudança. Por isso, são problemáticas interpretações - a exemplo do prefácio de José de Souza 
Martins à quinta edição (Martins, 2005, p. 9-23) - ávidas em aprisionar RBB num esquema domesticado e bipolar de modernidade e atraso, rural e urbano, ou seja, a possibilidade de mudar sem superar a "sociopatia".

As grandes obras deixam grandes perguntas. É tarefa intelectual de porte perscrutar a recente evolução brasileira à luz dos conceitos e das perguntas desatados de RBB: teríamos completado o ciclo da revolução burguesa entre nós com a assunção, especialmente depois da edição do Plano Real (1994), a uma nova fase da dependência pilotada por um Estado dependenterentístico? As constrições da dependência econômica realmente restringem até que ponto as possibilidades de desenvolvimento capitalista? É possível uma convivência de longo prazo, mais além dos ciclos de conjuntura, entre democracia e desenvolvimento econômico associado? Só o regime socialista, e nada mais, permite um desenvolvimento autônomo do Brasil? Ou é possível a autonomia do capitalismo, ou um regime misto, a partir de um bloco regional de nações geopoliticamente independentes?

\section{“Ecletismo bem temperado" e marxismo revolucionário}

O conteúdo radical da obra vinda a lume em 1975 significou também a conclusão de uma viragem no pensamento de Florestan. A partir daquele momento, o militante radicalizado pelas obras da ditadura abandona definitivamente a pele confortável e as perífrases de influente sociólogo - cultor paradoxal de um "ecletismo bem temperado, não simplesmente relativizador nem atomizador dos procedimentos analíticos” (Cohn, 1987, p. 50). Influente e reconhecido, mestre de vários discípulos intelectuais famosos no meio acadêmico (FHC, Octavio Ianni, Maria Sylvia de Carvalho Franco etc.), o autor se despe de capas protetoras e parte para o combate de peito aberto à ditadura com as armas da teoria marxista. Contudo, preste-se atenção, não o marxismo dos salões - que sobrevive da citação do autor francês em moda. Mas um marxismo revolucionário, 
fundamentado, principalmente, em autores da estatura de Marx, Engels, Lênin, Trotsky, Rosa Luxemburgo, José Martí, José Carlos Mariátegui, Che Guevara, Fidel Castro etc.; como também da excelente economia política e teoria política marxistas dos anos 1960/70, Ernest Mandel, Harry Magdoff, Ralph Miliband, Nicos Poulantzas, entre outros.

Durante muito tempo, Florestan foi um sociólogo dedicado a contribuir com soluções metodológicas originais para os desafios epistemológicos do ofício científico-acadêmico rigoroso em pesquisa sociológica empírica. Havia nessa labuta uma nítida e produtiva fragmentação ontoexistencial, pois ele cuidava de separar escrupulosamente dois momentos de seu espírito, a vocação revolucionária e o trabalho científico. Escreve o nosso autor: "fiquei como uma pessoa dividida ao meio, entre o sociólogo e o socialista” (Fernandes, 2006, p. 31).

Observe-se, em favor do projeto originário, que ele se incumbiu de privilegiar, na condição de objetos de pesquisa, os chamados excluídos da história, os índios, os negros, os imigrantes e os trabalhadores. Para reconstruir, em forma de saber científico, as agruras de todos esses excluídos da história, o compromisso ético era imprescindível, mas insuficiente. Seria necessário conhecer esses objetos a fundo, utilizar e inovar instrumentalmente métodos e teorias hauridos da tradição acadêmica sociológica, mas especialmente ansiar, através de uma leitura rigorosa, o domínio, ainda ralo na tradição bacharelesca das humanidades brasileiras, dos clássicos do cânone da disciplina. Atuando nas sombras, tal projeto fazia sentido naquele momento do país moldado pelo bloco histórico de 1930, de modernização institucional e adensamento do capitalismo brasileiro.

Muito importante observar que, no labor de desenvolver uma escola científica sociológica em São Paulo, Florestan jamais palmilhou pela cilada de operar uma síntese eclética de pensadores como Marx, Weber e Durkheim: "o estudo que fiz de Marx e Engels levou-me à conclusão de que não se podiam fundir pensamentos que são opostos. Seria muito mais fecundo procurar a razão de ser de sua diferença específica. Eu 
começava a enfrentar, assim, a questão de saber qual é a contribuição teórica específica de Durkheim, de Marx, de Max Weber etc., e por aí tentei descobrir as respostas" (Fernandes, 2006, p. 17).

Seu "ecletismo bem temperado" é sistêmico, é uma forma muito particular, inusitada e não despropositada de produzir uma síntese dialética original. Marx chegou à dialética através da suprassunção de Hegel, mas são possíveis outros caminhos, antes e depois desse caso notável, de chegar a ela. Por isso, como escreveu Gabriel Cohn corretamente (1986, p. 125-148; 1987, p. 48-53), na busca de fundamentos empíricos - e não simplesmente de teoria pura - na reconstrução de um objeto de conhecimento, Florestan se valeu de tipos, entre os principais, o weberiano (tipo ideal), o durkheimiano (tipo médio) e o marxista (tipo extremo). Nosso autor sempre trabalha duro em sua oficina o máximo material empírico coletado, costurando por dentro e de maneira tensa (Florestan é um autor de linguagem tensa) uma elucidação pesquisada - à falta de um termo mais adequado - de tónus materialista.

Mas seria dialético? Gramsci escreveu, com razão, que toda grande pesquisa cria seu próprio método: "toda pesquisa científica cria para si um método adequado, uma lógica própria” (Gramsci, 1999, p. 234-235). O procedimento original de Fernandes, embora diste da tentação de fundir alhos com bugalhos, por outro lado resultava em convívio com tensões e torções de linguagem até chegar à ourivesaria da categoria precisa, já saturada de pesquisa da realidade social. Por exemplo, sobre a burguesia brasileira, Florestan definiu, durante algum tempo, que nossa burguesia tinha um talhe histórico e estrutural "heteronímico", até porque a própria realidade solo brasileira é heteronímica. Sem dúvida, a burguesia brasileira é heteronímica, mas talvez esse traço não seja o termo mais adequado para descrever à saturação as determinações da realidade a partir de certo momento. Certamente, por isso, depois de muita pesquisa empírica e teórica, nosso autor passou a preferir o termo "burguesia dependente" para descrever a transição brasileira do 
capitalismo concorrencial para o capitalismo monopolista emergente depois de 1930 e do pós-guerra. À sua maneira, a revolução burguesa no Brasil é um tipo, mas não um tipo ideal weberiano, como às vezes alguns estudiosos de Florestan classificam, mas uma totalidade reconstruída do abstrato ao concreto, entre outros recursos heurísticos, por meio de três tipos. O mais importante é que, distinta, por exemplo, do tipo ideal weberiano - que é sempre uma reconstrução ideal da realidade movida pela subjetividade do sujeito do conhecimento (o pesquisador) - , a reconstrução florestiana se pretende materialista.

Tome-se o exemplo da sempre complexa discussão sobre o conceito de classes sociais. Como são muitas as dificuldades de explicar o conceito de classes como chave explicativa da estrutura da sociedade colonial, Florestan preferiu designar nossos primeiros grupos sociais dominantes como "estamentos". E. P. Thompson (1989, p. 13-61), em outra chave teórica, aventou a possibilidade, na experiência de formação da classe operária inglesa, de uma "luta de classes sem classes". No Brasil, elaborando por conta e risco, Florestan adotou a terminologia de transição a uma "ordem social competitiva" (ou seja, o processo de transição desde uma ordem escravista até uma sociedade capitalista) para não perder de vista as particularidades das relações, dualmente escravistas e patriarcais, que aqui vicejaram.

De todos os conceitos originais criados pelo autor, um dos mais heterodoxos é o de "ordem social". Escreve Heloísa Fernandes, em e-mail ao autor deste artigo: "[...] eu costumava discutir com o meu pai sobre o ecletismo, mas, hoje, penso que o 'ecletismo bem temperado' do Florestan permitiu que ele inventasse o conceito de ordem social - sei que é de marca weberiana, mas é uma invenção do Florestan, porque, para Weber, a ordem capitalista, definindo-se pelo mercado, é uma ordem econômica, enquanto a ordem social é mais propriamente a estamental e de castas, que se define pelo modo de vida. De todo modo, digo eu, esse conceito de ordem social é o que há de mais rico no Florestan porque, 
graças a ele, como escrevo [...], 'o sociólogo manteve-se atento à exclusão da maioria da plena cidadania, e o socialista não submergiu numa narrativa teleológica das classes sociais'”.

Para mim, é ainda mais: entender as origens do capitalismo brasileiro na chave de "ordem social" permite integrar à análise - mais ou menos à maneira do conceito de "bloco histórico" em Gramsci - blocos temporais relativamente longos amalgamando economia, cultura e política, integrando estrutura e superestrutura em mútua incidência à totalidade social. Por tudo isso, parece-me que a opção teórica e existencial de Fernandes pelo marxismo processou-se por uma via bastante pessoal e original. O marxismo peculiar de Fernandes, mesmo na fase mais madura, abertamente revolucionária, tem uma dicção própria e inimitável, como um jogo dialético de linguagem em que a terminologia do "ecletismo bem temperado" surge no "marxismo revolucionário", assim como, muitas vezes, no passado, a dicção do "marxismo revolucionário" surpreende no "ecletismo bem temperado". Curiosamente — brasileiramente? —, a dicção da escrita de Florestan sempre é eivada da presença conteudística do marxismo, de expressões hauridas da antropologia funcionalista estadunidense, da sociologia estruturalista da Escola de Chicago, da sociologia da cultura de Karl Mannheim etc. Porém, conquanto a exposição esteja permeada da nomenclatura haurida da sociologia e da antropologia canônicas, a investigação é feita sob os auspícios de um método dialético de análise, no qual se situa esse inimitável e particularíssimo "ecletismo bem temperado".

Assim, havia em Florestan uma disjuntiva: no plano estritamente político, Fernandes sempre esteve situado à esquerda e professou o marxismo, mas, no plano conceitual, a passagem para o marxismo realizou-se em um longo prazo e com crispações de pensamento, revelado pelo resíduo funcionalista no plano da exposição. Diz-nos Florestan (1995, p. 15): “[...] durante algum tempo, eu corri o risco de palmilhar o caminho [...] de pulverizar as ciências e de procurar uma falsa autonomia das ciências. Eu teria entrado por um mau caminho. O que me salvou 
foi a impregnação marxista da minha relação ética com os problemas da sociedade brasileira".

\section{A revolução burguesa na chave do capitalismo subdesenvolvido e dependente}

Um dos efeitos mais importantes desse marxismo personalíssimo é que problemáticas, categorias e conceitos, por longo tempo ladrilhados no âmbito da tradição marxista, retornam enfim com vigorosa força heurística em RBB. Trata-se de um trabalho vivo e criativo, não apenas de aplicação ou transposição integral. Florestan partia da realidade para o conceito, em vez de do conceito para a realidade, ciente (ele repetiu muitas vezes essa lição hegeliana) de que é preciso não apenas que a realidade tenda ao conceito, mas também que o conceito tenda à realidade. A recepção desse paiol de autores, categorias e conceitos oriundos da tradição marxista deve ser vista mais como incorporação do "estado das artes" da teoria, a ser, como ele gostava de dizer, 'saturado' de pesquisa empírica, uma pesquisa com potencial de corrigir, desviar ou negar um a priori dogmático, venha da autoridade que vier. Toda a obra de Florestan, inclusive a parte mais abertamente marxista, escapa, portanto, de um pálido jogo de influências de autores importantes e da aplicação de categorias externas. Por isso, é desprovido de fidelidade ao método de investigação do autor filiá-lo dogmaticamente a uma corrente marxista, seja o luxemburguismo, seja a teoria da dependência, seja o trotskismo.

Como exemplos disso, tem-se a maneira como Florestan aborda temas clássicos do marxismo e do desenvolvimento. Ele resgata Lênin, por exemplo, na questão da formação do mercado interno numa economia de capitalismo periférico e no controle das regiões mais atrasadas pelas mais adiantadas, um dos temas mais caros na discussão do desenvolvimento por um viés, relembrando Francisco de Oliveira (2003b), de uma "crítica da razão dualista". Lênin estava sendo universal tratando da aldeia, por isso Florestan considera $O$ desenvolvimento do capitalismo na 
Rússia (1982a) “[...] sua maior obra de investigação científica” (Fernandes, 19p. 252). Também considera Lênin na questão da voragem expansiva do imperialismo contemporâneo, estudado por esse autor em Imperialismo, fase superior do capitalismo (1982b). São dois livros que comparecem, não por acaso, especialmente citados em RBB na seção intitulada pelo próprio Florestan de "Bibliografia de referência” (Fernandes, 2005, p. 426). Também se deve destacar, a propósito, a menção de Rosa Luxemburgo em A acumulação do capital (1985), feita na mesma seção "Bibliografia de referência” (Fernandes, 2005, p. 426). Lênin e Rosa são importantes (mais Lênin que Rosa), mas ele não repete, processa a seu modo e tira suas próprias conclusões. Segundo Florestan, embora Rosa tenha sido uma pioneira em perceber o conteúdo expansivo e militar do capitalismo rumo à ocupação colonial da periferia, visando aplicar os capitais sobrantes gerados no centro, ainda assim, em que pese a genialidade de uma análise de mérito inaugural, "percebe-se que ela não está interessada nos mecanismos que ocorrem na periferia", ao passo que a teoria leninista do imperialismo seria mais geral e inclusiva. Ao relevar a teoria do imperialismo, Florestan não acha "que a teoria da dependência seja uma teoria nova. Ela é um desdobramento da teoria do imperialismo" (Fernandes, 2006, p. 41). ${ }^{1}$

Outro parâmetro-chave dos clássicos do marxismo nas análises de Florestan sobre a formação social brasileira seria, no entender de Osvaldo Coggiola (1995, p. 9), a noção histórica de desenvolvimento desigual e combinado do capitalismo considerado em plano mundial, desenvolvida por Trotsky. Na juventude trotskista, como bem observa Coggiola (tal evidência, às vezes, é esquecida ou escamoteada nos estudos acadêmicos), nosso autor conheceu as elaborações clássicas de Trotsky. Com certeza, Florestan tinha por Trotsky e suas teorizações elevada consideração, como se deduz da leitura de seu pequeno artigo "Trotsky e a revolução"

Observe-se que Florestan em RBB é bastante econômico em citar bibliografia no texto. A extensa bibliografia de RBB, coordenada por Florestan, foi organizada a posteriori à redação do livro pelo sociólogo Paulo Silveira. 
(Fernandes, 1994, p. 187-192). No entanto, na seção do livro em que ele cuida de revelar sua "bibliografia de referência", Florestan cita de Trotsky uma única obra, Revolução e contrarrevolução na Alemanha (1979), uma extraordinária seleta de textos de combate à ascensão do nazifascismo e crítica à linha dominante na Internacional Comunista de "classe contra classe". O livro de Trotsky trata-se de uma obra de teoria política marxista, mas não tem a ver, ou apenas em uma segunda mediana tem a ver, com questões de economia política do imperialismo mundial. Aparentemente, grita pela falta na "bibliografia de referência" de RBB, dos livros e dos artigos em que Trotsky aborda precipuamente o desenvolvimento desigual e combinado. Mas não é assim. Essas leituras já foram assimiladas organicamente, compõem a bagagem teórico-política, e não apenas memorialística, de nosso autor. Em RBB, Florestan radicaliza no conceito de 'ensaio de interpretação sociológica' — que já era o subtítulo de A integração do negro na sociedade de classes -, no sentido de uma exposição de muitas referências ocultas, devidamente sintetizadas, e poucas citações diretas.

No que tange aos autores da teoria da dependência, na vertente marxista, dois são citados na seção de "Bibliografia de referência" na parte sobre a América Latina: André Gunder Frank e Ruy Mauro Marini. No outro espectro do dependentismo, mais weberiano, seu ex-aluno FHC, o Papai Noel da teoria da dependência associada, comparece com todas as suas publicações. Em outras ocasiões, ressalvando a importância de Marini na compreensão da dinâmica do capitalismo latino-americano e brasileiro, no entanto, Florestan fez ressalvas ao tratamento da questão agrária no Brasil por separar o atraso do latifúndio da burguesia, "quando na verdade o setor mais reacionário da burguesia brasileira é o latifúndio. Foi o setor que deu o salto mais rápido no sentido de passar a uma condição aristocrática para uma condição burguesa" (Fernandes, 1980b, p. 30). Como não poderia deixar de comparecer em um balanço sobre a RBB, praticamente todos os autores relevantes da CEPAL (Comissão Econômica para a América Latina e o Caribe) e do ISEB (Instituto Superior de Estudos Brasileiros) constam na bibliografia. De Lênin 
(já citado anteriormente neste artigo, junto a Rosa Luxemburgo, como referências polares), curiosamente, Florestan não cita o importantíssimo, para o estudo do tema de tipos heterodoxos e vias não clássicas de revolução burguesa, Programa agrário (1980), onde aflora a questão da "via prussiana" de resolução da questão agrária.

Penso que a questão da dependência, no enfoque original de Florestan, constitui uma das bases da interpretação do autor sobre o processo de RBB. Sem a lupa desse enfoque, a narrativa do processo de RBB torna-se incompreensível. Vale observar que, em que pese a relevância - a 'terceira parte' de RBB chamada de 'revolução burguesa e capitalismo dependente' (2005, p. 235-424) —, no diálogo de Florestan com os dependentistas, ele abordou a questão da dependência por um viés próprio. Perscrutou a realidade a partir do conhecimento empírico e bibliográfico acumulado anos a fio de pesquisa sobre o Brasil, saturando de conteúdo pensado o que ele chamava de "ordem social burguesa", ao passo que os dependentistas, na vertente marxista, abordaram a mesma ordem a partir de questões postas por uma nova economia política, como a transferência de valor e a superexploração da força de trabalho. Gramsci cunhou a noção de "tradução" e "tradutibilidade" das linguagens científicas e sociais, ou seja, a possibilidade de uma linguagem científica encontrar uma tradução em outra (Gramsci, 1999, p. 185-190). É o caso das relações entre Florestan e a Teoria Marxista da Dependência.

O Brasil não é Uganda, Afeganistão, Haiti ou Porto Rico, mas também não é Estados Unidos (revolução clássica), Japão ou Alemanha (capitalismos tardios não coloniais). Nossa burguesia, na transição para o capitalismo monopolista, não é simplesmente uma burguesia neocolonial: "ao contrário do chavão corrente, as burguesias não são, sob o capitalismo dependente e subdesenvolvido, meras 'burguesias compradoras' (típicas de situações coloniais e neocoloniais, em sentido específico). Elas detêm um forte poder econômico, social e político, de base e alcance nacionais" (Fernandes, 1987, p. 296). Para compreender essa definição, deve-se mergulhar na história do país. 
Na contramão de muita literatura originária de São Paulo, que destacava mais a acumulação prévia do excedente da burguesia mercantil cafeeira no Império - ou seja, a continuidade do processo de inserção do Brasil no capitalismo competitivo - , que o capitalismo de comando varguista rumo ao capitalismo monopolista, Florestan valorizou o processo originário de 1930 - verdade que numa embocadura muito particular, desalinhada das tradições dominantes na época entre trabalhistas e comunistas, afinal, o ISEB e o PCB são os dois principais agentes da crítica respeitosa do autor.

As primícias de uma lenta revolução burguesa no regime de capitalismo tardio vinham de antes de 1930. Contudo, a situação ali criada abriu uma brecha política: a possibilidade de apostar idealmente num projeto de desenvolvimento autônomo do capitalismo brasileiro. Tal projeto autonomista, revolucionário para uns, reformista para outros, tocou os derradeiros acordes sinfônicos em 1964. Depois, virou elegia. Segundo Florestan, "o antigo regime não entra em crise final quando desaparece a escravidão: isso só acontece em 1930 [...]. Isso não significa, porém, o desaparecimento da oligarquia, com seu obscurantismo intelectual e sua propensão reacionária. Mas, de qualquer maneira, o antigo regime, que deveria sofrer um colapso com a abolição e a proclamação da República, entra finalmente em agonia e perde a base material de seu precário equilíbrio social e político" (Fernandes, 2006, p. 26-27).

O Brasil conheceu, depois de 1930, assentado no processo anterior de transição do trabalho escravo ao trabalho livre, da transição de 1888, um período de grande desenvolvimento econômico. Começou um acendrado processo de mudança social. O país passou de uma formação econômico-social agrário-exportadora e de dominância de variadas relações sociais pré-capitalistas (vinculadas ao contexto da divisão internacional do trabalho do chamado "imperialismo clássico") para o capitalismo que Florestan denominou de síntese de capitalismo dependente e subdesenvolvido sob a égide de um capitalismo monopolista. Vale dizer, um vigoroso processo interno de industrialização e modernização, mas em contexto de amálgama, formador de uma estrutura dual, entre o capital 
monopolista externo, as frações da burguesia brasileira e a persistência no campo de relações sociais pré e subcapitalistas.

Por isso, não é possível fantasiar esse período. Houve um processo de desenvolvimento econômico, crescimento industrial, urbanização e fortalecimento da sociedade civil ampliada, mas, não ao talante de saltar por cima das vicissitudes e das constrições do processo de desenvolvimento desigual e combinado do capitalismo mundial, em que o Brasil está situado na esfera dependente. Esse é o ponto frágil do nosso processo de modernização: não ocorreu entre os países latino-americanos mais viáveis (Brasil, México e Argentina), que saltaram da periferia para a semiperiferia do capitalismo durante a vigência da onda longa expansiva, de 1945-1972, um processo de industrialização orgânico, uma autonomização da dependência. O motivo da industrialização atada e da reverberação da dependência guarda relação com a maneira sui generis como ocorreu o processo de RBB: “a 'revolução burguesa' no Brasil não se deu pela burguesia nacional, mas pelo capital monopolista. É o imperialismo que tem o papel hegemônico e realiza os papéis dos prussianos ou então da dinastia Meiji” (Fernandes, 1989, p. 136).

Para Florestan, houve, de fato, e não como ausência, simulacro ou nostalgia de um futuro do pretérito, a materialidade de uma RBB. $O$ título do livro não é uma graciosa metáfora. Nessa percepção, ele abre uma diferença com os estudos de modernização conservadora, de autores como Barrington Moore Jr. (1975), para quem a última revolução burguesa foi a estadunidense, por isso sociedades que não fizeram a revolução agrária não conseguiram transitar para o regime político de liberalismo democrático. A revolução burguesa, em vez de uma limitada “modernização conservadora”, é exatamente o processo que Florestan designa de "transformação capitalista" na época e pela via do capitalismo dependente sob a égide do capitalismo monopolista.

Ao utilizar a expressão revolução burguesa para designar o processo de modernização das estruturas produtivas e sociais do Brasil, Florestan não está utilizando o conceito ao molde de identidade com as revoluções 
burguesas clássicas, como, principalmente, a francesa e a norte-americana. Tem-se aqui uma utilização heterodoxa do conceito de revolução burguesa, referente a um processo de longa duração: o lento processo brasileiro de transição ao capitalismo. A heterodoxia desse conceito de revolução burguesa visa apanhar não apenas as características revolucionárias de uma revolução, mas, também, paramenta as contrarrevolucionárias, em especial o reforço pelo capital monopolista forâneo das relações pré e subcapitalistas internas.

Observe-se que esse uso heterodoxo do conceito de revolução provocou objeções, entre elas, uma escrita por Jacob Gorender, para quem Florestan cunhou um conceito "seu" de revolução burguesa, desdobrado numa temporalidade estendida: "a revolução burguesa é um processo histórico concentrado em alguns anos ou alguns decênios, mediante o qual a burguesia se apossa do poder de Estado, torna-se classe dominante e transforma o regime político jurídico em favor da expansão desembaraçada das relações de produção capitalistas [...] [É] inaplicável ao Brasil o conceito de revolução burguesa. Em nosso país, a abolição e a República fizeram as vezes da revolução burguesa" (Gorender, 1987b, p. 250-259).

Existe um elemento importante de "história universal" — no sentido hegeliano, filtrado por Marx de uma "humanidade universal" — no pensamento de Florestan, não detectado por Gorender, que legitima a utilização estendida da revolução burguesa. Florestan tem em mira a realidade histórica de que as revoluções burguesas clássicas foram poucas e concentradas nos finais do século XVIII e na primeira metade do século XIX. Aquele veredicto exarado por Marx e Engels no balanço do fracasso das chamadas revoluções de 1848 na França e no resto da Europa, certamente, é levado em consideração por Fernandes. Daquela data em diante, a burguesia fez um giro histórico definitivo restaurador e conservador, continuou até recentemente progressista/progressiva (depois do processo de RBB como "história universal", nem isso), no sentido de ser uma classe social interessada no desenvolvimento das forças produtivas, mas passou a ser radicalmente contrarrevolucionária. É desse elemento de história universal do processo de revolução burguesa, que 
um autor como Gramsci, em tour de force paralelo ao de Florestan, por exemplo, extrai o conceito de revolução passiva. Com nomenclatura distinta, a revolução burguesa de Florestan tem mais a ver com a questão da revolução passiva em Gramsci (Coutinho, 2011, p. 221-240) do que com as modernizações conservadoras à la Barrington Moore Jr. (1975).

A revolução burguesa prolongada gerou uma burguesia incapaz de conduzir autonomamente a transformação capitalista - portanto, de conciliar internamente processos de hegemonia das revoluções clássicas. Houve revolução burguesa, mas não revolução nacional, popular e democrática. Precisou-se do capitalismo monopolista dos países centrais e das burguesias externas para levar a cabo a transformação. Mas, nem por isso, e talvez por causa disso, nossa burguesia jamais deixou, em todo o processo de transformação capitalista, de ocupar e controlar as rédeas a ferro e fogo, diretamente ou por meio de testas de ferro, o poder econômico, social e político da sociedade brasileira. Do ponto de vista da cultura - essa questão merece estudos à parte - , em virtude de que nossa RBB não conduzia a um processo histórico de hegemonia (ou uma hegemonia truncada, de autocracia burguesa), o domínio e o consenso das classes populares processaram-se pela via individual de integração através da indústria cultural, e não pela via orgânica nacional-popular.

Ora, conquanto encetada com o objetivo de dar acesso interno ao capital monopolista estrangeiro, não houve uma ocupação direta do Estado brasileiro por títeres estrangeiros. O Brasil não mantinha as mesmas relações de forças neocoloniais de uma Cuba de antes da revolução. A RBB foi dirigida politicamente pela burguesia brasileira, da direção política ela não abriu mão e por muito tempo. Por outro lado, ao inverso da transformação capitalista não clássica dos capitalismos tardios, por exemplo, da Alemanha, o ponto de apoio brasileiro não veio tão somente dos estamentos aristocráticos da burocracia estatal civil e militar interna, fortemente nacionalistas. Essa deficiência nacional teve de ser substituída pela participação, no próprio bloco histórico interno, dos interesses das nações capitalistas hegemônicas. 
A situação teve uma imediata reverberação política: mantendo-se o status quo das relações internacionais, não se interditou ao Brasil o desenvolvimento econômico nem a industrialização, desde que seja um desenvolvimento dependente e uma industrialização subdesenvolvida.

\section{Referências}

COGGIOLA, Osvaldo. Florestan Fernandes e o socialismo. In: FLORESTAN, Fernandes. Em busca do socialismo: últimos escritos e outros textos. São Paulo: Xamã, 1995.

COHN, Gabriel. Padrões e dilemas: o pensamento de Florestan Fernandes. In: MORAES, Reginaldo; ANTUNES, Ricardo; FERRANTE, Vera B. Inteligência brasileira. São Paulo: Brasiliense, 1986.

COHN, Gabriel. O ecletismo bem temperado. In: D’INCAO, Maria Angela. O saber militante: Ensaios sobre Florestan Fernandes. São Paulo: Fundação Editora Unesp; Paz e Terra, 1987.

COUTINHO, Carlos Nelson. Marxismo e "imagem do Brasil" em Florestan Fernandes. In: COUTINHO, Carlos Nelson. Cultura e sociedade no Brasil: ensaios sobre ideias e formas. 4. ed. São Paulo: Expressão Popular, 2011. p. 221-240.

FERNANDES, Florestan. Brasil: em compasso de espera. São Paulo: Hucitec, 1980a.

FERNANDES, Florestan. Florestan Fernandes, a pessoa e o político. Ensaio, São Paulo, n. 8, p. 9-40, 1980 b.

FERNANDES, Florestan. A revolução burguesa no Brasil: ensaio de interpretação sociológica. 3. ed. Rio de Janeiro: Guanabara, 1987.

FERNANDES, Florestan. Florestan Fernandes: constituinte e revolução. Ensaio, São Paulo, n. 17-18, p. 123-158, 1989.

FERNANDES, Florestan. Trotsky e a revolução. In: COGGIOLA, Osvaldo. Trotsky hoje. São Paulo: Ensaio, 1994, p 187-192.

FERNANDES, Florestan. Florestan Fernandes, história e histórias. Depoimento a Alfredo Bosi, Carlos Guilherme Mota e Gabriel Cohn. Novos Estudos Cebrap, São Paulo, n. 42, p. 3-31, jul. 1995.

FERNANDES, Florestan. A revolução burguesa no Brasil: ensaio de interpretação sociológica. 4. ed. São Paulo: Globo, 2005, p. 426.

FERNANDES, Florestan. Florestan Fernandes. Entrevista. In: RUGAI BASTOS, Elide et al. Conversas com sociólogos brasileiros. São Paulo: Editora 34, 2006. p. 13-48. 
FERNANDES, Florestan. Marx, Engels, Lênin. A história em processo. São Paulo: Expressão Popular, 2012, p. 252.

GRAMSCI, Antonio. Cadernos do cárcere. Rio de Janeiro: Civilização Brasileira, 1999. v. 1: Introdução ao estudo da filosofia. A filosofia de Benedetto Croce.

GORENDER, Jacob. Combate nas trevas. A esquerda brasileira: das ilusões perdidas à luta armada. São Paulo: Ática, 1987a.

GORENDER, Jacob. A revolução burguesa e os comunistas. In: D’INCAO, Maria Ângela. O saber militante: ensaios sobre Florestan Fernandes. São Paulo: Paz e Terra; Fundação Editora Unesp, 1987b. p. 250-259.

LÊNIN, Vladimir I. O programa agrário da social-democracia na primeira revolução russa de 1905-1907. São Paulo: Ciências Humanas, 1980.

LÊNIN, Vladimir I. O desenvolvimento do capitalismo na Rússia: o processo de formação do mercado interno para a grande indústria. São Paulo: Abril Cultural, 1982a.

LÊNIN, Vladimir I. O imperialismo, fase superior do capitalismo. In: LÊNIN, Vladimir I. Obras escolhidas. 2. ed. São Paulo: Alfa-Ômega, 1982b. v. 1.

LUXEMBURG, Rosa. A acumulação do capital: contribuição ao estudo econômico do imperialismo. São Paulo: Nova Cultural, 1985.

MARTINS, José de Souza. Prefácio à quinta edição. In: FERNANDES, Florestan. A revolução burguesa no Brasil: ensaio de interpretação sociológica. 5. ed. Rio de Janeiro: Globo, 2005.

MOORE JR., Barrington. As origens sociais da ditadura e da democracia. São Paulo: Martins Fontes, 1975.

OLIVEIRA, Francisco de. A navegação venturosa: ensaios sobre Celso Furtado. São Paulo: Boitempo, 2003a.

OLIVEIRA, Francisco de. Crítica à razão dualista/o ornitorrinco. São Paulo: Boitempo, 2003b.

PRESTES, Anita Leocádia. Luiz Carlos Prestes: o combate por um partido revolucionário (1958-1990). São Paulo: Expressão Popular, 2012.

PRESTES, Luiz Carlos. Brasil. In: VÁRIOS AUTORES. Socialismo em debate (1917-1987). São Paulo: Cajamar, 1988. p. 223-304.

SODRÉ, Nelson Werneck. História e materialismo histórico no Brasil. São Paulo: Global, 1985.

THOMPSON, Edward Palmer. La sociedad inglesa del siglo XVIII: ¿lucha de clases sin clases?. In: THOMPSON, Edward Palmer. Tradición, revuelta y consciencia de clase: estudios sobre la crisis de la sociedad preindustrial. Barcelona: Crítica, 1989. 
TROTSKY, Leon. Revolução e contrarrevolução na Alemanha. São Paulo: Ciências Humanas, 1979.

VÁRIOS AUTORES. A revolução burguesa no Brasil. Encontros com a Civilização Brasileira, Rio de Janeiro, n. 4, p. 175-207, out. 1978.

\section{Sobre o autor}

Jaldes Meneses - Professor titular do Departamento de História, doutor em Serviço Social e membro permanente do Programa de Pós-Graduação em Serviço Social (UFPB).

E-mail: jaldesm@uol.com.br 